Review

\title{
Endometriosis-associated Ovarian Clear Cell Carcinoma: A Special Entity?
}

\author{
Yue Sun ${ }^{1,2}$ and Guoyan $\operatorname{Liu}^{1,2}$ \\ 1. Department of Gynecology and Obstetrics, Tianjin Medical University General Hospital, Tianjin, 300052, China. \\ 2. Tianjin Key Laboratory of Female Reproductive Health and Eugenics, Tianjin, 300052, China. \\ $\triangle$ Corresponding author: Dr. Guoyan Liu, Department of Gynecology and Obstetrics, Tianjin Medical University General Hospital, Tianjin, 300052, China. Tel: \\ +86-022-60363769; E-mail: liuguoyan211@tmu.edu.cn. \\ (C) The author(s). This is an open access article distributed under the terms of the Creative Commons Attribution License (https://creativecommons.org/licenses/by/4.0/). \\ See http:/ / ivyspring.com/terms for full terms and conditions.
}

Received: 2021.03.30; Accepted: 2021.09.12; Published: 2021.09.23

\begin{abstract}
Endometriosis is an estrogen-dependent disease, which serves as a precursor of ovarian cancer, especially clear cell carcinoma (OCCC) and endometrial carcinoma. Although micro-environmental factors such as oxidative stress, immune cell dysfunction, inflammation, steroid hormones, and stem cells required for malignant transformation have been found in endometriosis, the exact carcinogenic mechanism remains unclear. Recent research suggest that many putative driver genes and aberrant pathways including ARIDIA mutations, PIK3CA mutations, MET activation, HNF-1 $\beta$ activation, and miRNAs dysfunction, play crucial roles in the malignant transformation of endometriosis to OCCC. The clinical features of OCCC are different from other histological types. Patients usually present with a large, unilateral pelvic mass, and occasionally have thromboembolic vascular complications. OCCC patients are easier to be resistant to chemotherapy, have a worse prognosis, and are usually difficult to treat. To improve the survival of OCCC patients, it is necessary to better understand its specific carcinogenic mechanism and explore new treatment strategy, including molecular target.
\end{abstract}

Key words: endometriosis; ovarian clear cell carcinoma; malignant transformation; clinical features

\section{Introduction}

Endometriosis is a common estrogen-dependent disease in which endometrium grows outside the uterus. This complex disease affects approximately $7-15 \%$ of women of reproductive age. Although endometriosis is identified as a morphologically benign disease, it has characteristics similar to invasive neoplasms, such as peritoneal implants, local invasion and distant metastasis. Evidence suggests that endometriosis, especially ovarian endometriotic cyst, may be a monoclonal neoplastic disease with premalignant potential [1]. Therefore, the risk of development of ovarian cancer arise from endometriosis cannot be ignored.

A large-scale epidemiological study using more than 20,000 women with endometriosis first found that the incidence of ovarian cancer has increased significantly [2]. Subsequent studies have found that $5-10 \%$ of endometriosis patients have ovarian cancer, but the number is sometimes different. Studies have shown that endometriosis increases the risk of ovarian cancer by about 1.2-1.8 times [3]. During follow-up of endometrial cysts in Murakami's study, $75 \%$ of patients progressed to ovarian cancer within 5 years and most patients progressed within 10 years [4].

Endometriosis is a risk factor for ovarian cancer. It is believed that endometriosis-associated ovarian cancer (EAOC), most commonly ovarian clear cell carcinoma (OCCC), develops from ovarian endometrial cysts. OCCC is a specific pathological type of epithelial ovarian carcinoma (EOC) with unique clinical and molecular features [5]. Patients usually present with a large, unilateral pelvic mass, and occasionally have thromboembolic vascular complications or hypercalcemia [6, 7]. OCCC displays chemo-resistance to platinum, the efficacy of platinum-based chemotherapy is only $20 \%$ to $50 \%$ for OCCC. OCCC patients have a worse prognosis, and are usually difficult to treat $[8,9]$. The molecular changes in OCCC have not been completely elucidated. A deeper understanding of pathology and mechanisms of carcinogenesis is needed to develop a specific treatment strategy, including molecular 
targeting. Considering the increasing attention to this topic, the article summarizes the current knowledge about the problem.

\section{Epidemiology of endometriosis- associated OCCC}

OCCC is the second most common EOC, first recognized as a unique histologic subtype by the World Health Organization in 1973 [10, 11]. The prevalence of OCCC differed by region. It accounts for $3.1 \%-11.1 \%$ of EOC in the United States, but it has a higher prevalence in East Asia, accounting for $25 \% \sim 30 \%$ and $10.3 \% \sim 11.6 \%$ of EOCs in Japan and Korea, respectively [12-14]. A possible link between endometriosis and OCCC in certain cases has been suggested for a long time. Since Sampson described an EAOC for the first time in 1925, multiple studies have assessed the incidence of endometriosisassociated OCCC [15]. In a large register study of 20,686 Swedish women with endometriosis, the standardized incidence ratio for developing ovarian cancer during a mean follow-up of 11.4 years was 1.9 (95\% CI: 1.3-2.8) [16]. A pooled meta-analysis of 13 case-control studies including 7,911 women with ovarian cancer and 13,226 controls demonstrated that self-reported endometriosis was associated with a significantly increased risk of OCCC (odds ratio 3.05, 95\% CI 2.43-3.84, p<0.0001) [17]. Consistent observations were reported by a Danish register study, confirming that endometriosis was associated with increased risks for ovarian cancer (OR 1.34; 95\% CI: 1.16-1.55), due primarily to clear-cell types (OR 3.64; 95\% CI: 2.36-5.38) [18]. In the ENOCA population-based cohort study, the incidence of OCCC in a cohort of 131,450 women with a histological diagnosis of endometriosis was compared to an age-matched control cohort of 132,654 women with a benign dermal nevus. The age-adjusted incidence rate ratio (IRR) was 7.18 (95\% CI: 6.17-8.46) for ovarian cancer in women with endometriosis, and OCCC had the higher age-adjusted incidence rate ratio of 21.34 (95\% CI: 14.01-32.51) [19]. In summary, the lifetime risk for developing ovarian cancer is low with approximately $1.9 \%$. However, the risk for a woman with endometriosis to develop ovarian cancer is up to $50 \%$ higher than in the general population. This is particularly true regarding the risk for developing OCCC, where the risk is tripled, respectively.

\section{Pathological evidence that OCCC arises from endometriosis}

In 1925, the criteria for cancer arising from endometriosis was first proposed by Sampson, including that: (1) the tumor is adjacent to unequivocal foci of endometriosis, (2) there is no other primary tumor, (3) there are tissues resembling endometrial stroma surrounding epithelial glands [15]. Scott revised the criteria more stringently, requiring the transition from endometriosis to neoplastic epithelium [20]. Since LaGrenade reported the pathological continuation of atypical endometriosis to cancer lesions in seven cases of EAOC, more and more evidence supports that atypical endometriosis is an intermediate lesion between endometriosis and ovarian cancer [21]. First, compared with benign endometriotic cysts, atypical endometriosis is more common in endometriosis accompanied by malignant tumors [22, 23]. Atypical endometriosis was seen in $61 \%$ of EAOC, while it was observed in only $1.7 \%$ of endometriosis cases without cancer [23]. Substantial pathological data have showed the continuous transition from benign endometriosis to cancer, and atypical endometriosis may be observed in these areas [24]. Among the cancers, OCCC and endometrioid carcinomas are predominant for unknown reasons. Molecular analysis also indicated that there were multiple genetic events in atypical endometriosis, suggesting that the lesion has intermediate properties between benign endometriosis and ovarian cancer. Similar somatic mutations were identified in OCCC and adjacent atypical endometriosis, demonstrating that OCCC is not derived from the ovarian epithelium; rather, it represents tumor cells transformed from displaced endometriotic tissues [11, 25]. Therefore, atypical endometriosis is a precancerous lesion of OCCC.

\section{Pathogenesis involved in the malignant transformation of endometriosis to OCCC}

There are currently two main mechanisms to explain the relationship between OCCC and endometriosis. One is that endometriosis and OCCC share many of the same risk factors, including early menarche, late menopause and infertility. The common risk factors result in the occurrence of both diseases. Use of oral contraceptives, tubal ligation, and hysterectomy could decrease the risk of both diseases [26]. The other is that endometriotic cells gradually transform into cancer cells. The process of transformation from typical endometriosis, through atypical endometriosis, finally to OCCC seems to be mainly related to specific micro-environmental factors, molecular alterations and presence of stem cells. This article will focus on this part (Figure 1). 


\section{Endometriosis}

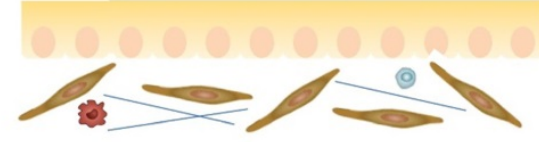

Atypical endometriosis

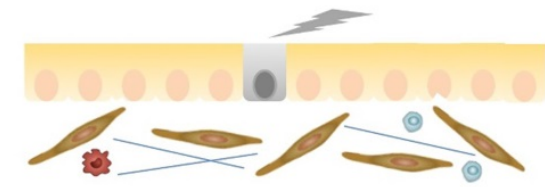

OCCC

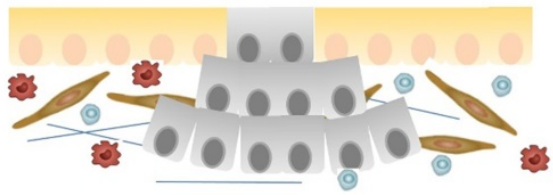

Steroid hormones

Oxidative stress

Inflammation

Epithelial Mutated Macrophages (O) B cells $\longrightarrow$ Fibroblasts

Figure 1. Mechanisms of progression from endometriosis to endometriosis-associated OccC. Some microenvironmental changes, as well as several genetic alterations, such as ARIDIA, PIK3CA mutations, and MET, HNF1 $\beta$ overexpression, were suspected to be associated with early carcinogenic events of OCCC.

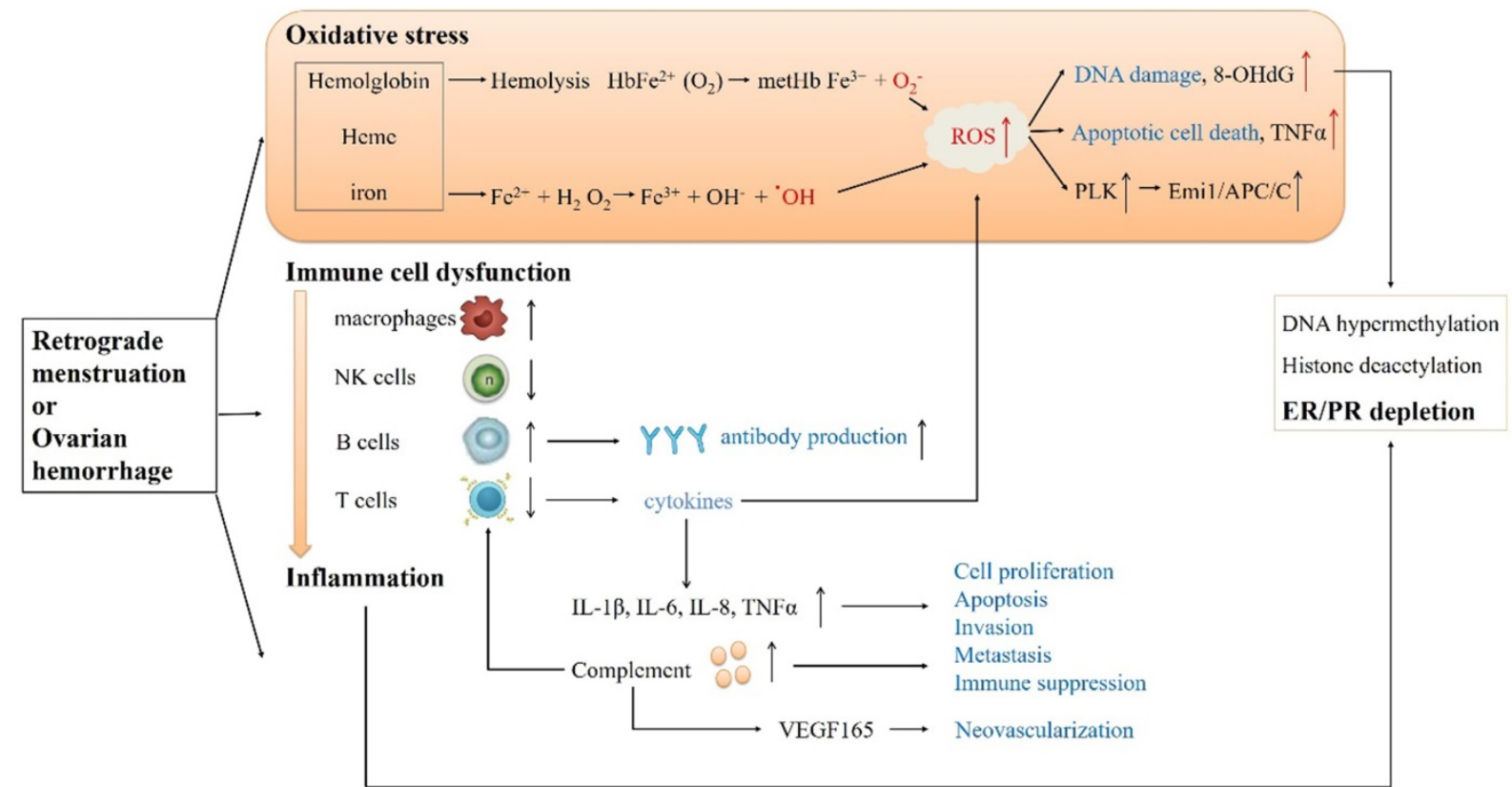

Endometriosis

Atypical endometriosis

OCCC

Figure 2. Alterations of microenvironment events in endometriosis-associated OCCC. In the endometriotic cyst, endometrial cells are exposed to the stresses of hypoxia, immune cell dysfunction and inflammation, eventually leading to OCCC.

\section{Alterations of microenvironment events}

The most well-known implantation theory about malignant transformation of endometriosis to OCCC has now been widely accepted, which posits that the viable menstrual endometrial cells were deposited in the pelvic cavity via retrograde menstruation and became the origin of ectopic endometrial tissue. These shed menstrual endometrial cells still capable to attach to the peritoneum, invade, proliferate, and differentiate [27]. The ovary is probably favored seeding sites for endometriosis cells especially in the ovulation sites [28]. Repeated bleeding of endometriosis cysts during the menstrual cycle causes changes in the microenvironment, resulting in the malignant transformation of endometriosis to OCCC (Figure 2). 


\section{Oxidative stress}

In the reproductive period, repeated hemorrhaging in endometriotic cysts induces excessive iron, cell-free hemoglobin, and heme accumulation. They are prone to autoxidation and might spontaneously convert oxyHb to metHb. Autoxidation of hemoglobin continuously generate $\operatorname{ROS}\left(\mathrm{O}_{2}{ }^{-}\right)$. Iron derivatives also stimulate Fenton reaction, increasing $\operatorname{ROS}(\mathrm{OH})$ production in endometriotic cyst. ROS could react with proteins, lipids and especially DNA, forming a possible source of carcinogenic mutations in the genome[29]. An oxidative stress marker as well as a biomarker of carcinogenesis, 8-hydroxydeoxyguanosine (8-OHdG) is formed when ROS interacts with DNA. Yamaguchi evaluated the contents of endometriotic cysts and found that free iron, 8-OHdG, lipid peroxidase, and lactose dehydrogenase levels were elevated compared to nonendometriotic cysts[30]. In addition, ROS can rapidly activate Polo-like kinases (PLK, a mitotic regulator) by regulating DNA replication under stressful conditions, thereby promoting genome stability. PLK phosphorylates Emi1 (Early mitotic inhibitor-1) to ensure that S-phase and mitosis entry are promoted by suppressing the anaphase-promoting complex/cyclosome (APC/C). Overexpression of Emi1 leads to mitotic catastrophe and genome instability and promotes tumorigenesis [31]. The latest data suggest that the Emi1/APC/C pathway is upregulated in atypical endometriosis during OCCC tumorigenesis [32]. Moreover, oxidative stress appears to be able to decrease the expression of ARID1A protein and mRNA levels in endometriotic cells, and low ARID1A gene activity in endometriosis may be a predisposing factor for the increased susceptibility of these lesions to the malignant transformation [33].

Hemoglobin and heme also alter the expression of many genes. Using microarray analysis, Mandai discovered 437 genes that are differentially expressed in OCCC. These genes were mainly related to oxidative stress and inflammation, which indicated that the cancer specifically expresses stress responsive genes [1]. Kajihara further supported the result that $87 \%$ of highly upregulated genes found in the OCCC are redox related genes, including oxidase and detoxification enzymes [34]. Accordingly, we speculate that the content of endometriotic cysts creates an environment of high oxidative stress, exposing epithelial cells to constant oxidative stress that may trigger the malignant transformation. OCCC acquires the ability to resist stress during the process of carcinogenesis in a stressful microenvironment, which may explain the observed OCCC chemotherapy resistance. However, the hypothesis should be further verified later.

\section{Immune cell dysfunction and inflammation}

Endometriosis is related to activated immune cells and abnormal cytokines in the peritoneal fluid, thereby forming a local inflammatory environment [35]. Inflammation of coelomic epithelial cellderivatives in the female reproductive tract is a major contributor to malignant transformation in endometriosis-associated OCCC [36]. There is substantial evidence of immune cell dysfunction in women with endometriosis: reduced $\mathrm{T}$ cell reactivity and NK cytotoxicity, increased B cell polyclonal activation and antibody production, increased number and activation of peritoneal macrophages, and changes in apoptotic pathways, which contribute to OCCC development [35, 37-41]. Endometrial fragments released during endometriosis can cause inflammation in the peritoneal cavity via neutrophils and macrophages recruited to the area [42]. However, peritoneal macrophages and NK cells in endometriosis cannot completely eliminate endometrial cells or fragments. The imbalance of $\mathrm{T}$ cells may result in abnormal secretion of cytokines (TNF- $\alpha$, IL-8 and VEGF, etc.) and inflammation, leading to endometrial lesions [43]. In addition, increased levels of several important cytokines such as IL-1 $\beta$, IL-2, IL-6, IL-8, and TNF- $\alpha$ in acute inflammatory phase have been found in peritoneal fluid of patients with endometriosis [44]. Similar to results in endometriosis, numerous studies suggest inflammatory cytokines promote the growth and progression of epithelial ovarian cancer, implying that inflammation is involved in the development of this disease [45]. Moreover, inflammatory cells may promote cell proliferation, angiogenesis, invasion, metastasis, production of ROS and inhibit apoptosis, contributing to DNA damage and mutations.

In recent years, studies have revealed new features of inflammation and pointed out previously unknown roles of complement in endometriosis and EAOC $[46,47]$. Complement proteins are abundant in epithelial cells of both benign and malignant lesions. Suryawanshi performed the immune gene expression analysis about pelvic inflammation firstly, and found five out of the total of nine genes differentially expressed in endometriosis and EAOC are complement genes, supporting the importance of complement cascade in these diseases. They further revealed that chronic inflammation in endometriosis is mainly determined by complement. Complement is still active in EAOC, while tumors with serous histology are not active, which further prove the heterogeneity of EAOC [47]. The complement system may contribute to the development of cancer through 
multiple mechanisms coexisting in the tumor environment either directly, by promoting tumor cell proliferation, or indirectly, by stimulating immune suppression and neovascularization [48, 49]. The production of complement $\mathrm{C} 5 \mathrm{a}$ in the tumor microenvironment enhances tumor growth through inhibiting anti-tumor CD8+ T cell mediated response, and pharmacological blockade of $\mathrm{C} 5 \mathrm{a}$ receptor significantly delays tumor growth [50]. In addition, complement inhibition blocks tumor growth by altering vascular endothelial cell function and VEGF165 expression [50]. And Su's recent study suggested that complement-activation-alternativepathway may be the crucial dysfunctional immunological pathway in duality for carcinogenesis at all OCCC stages [51].

Taken together, immune factors are obviously involved in the pathogenesis of endometriosis and OCCC. Many promising immune biomarkers may serve as potential therapeutic targets for the transition of endometriosis to OCCC in the future.

\section{Steroid hormones}

Endometriosis is an estrogen-dependent disease, and estrogen is closely related to the pathogenesis of ovarian cancer. However, estrogen receptors (ER) is significantly downregulated in OCCC compared to normal ovaries, endometriosis, therefore, endometriosis could become hormone-independent during the malignant transformation process [52]. Lack of hormone functioning may be a turning point in the development of OCCC [53]. The high expression of ER was retained in both distant and adjacent endometriotic lesions, but was lost in the primary OCCC, indicating a late carcinogenic event. The hypothesis concerning the carcinogenic pathogenesis of OCCC is that heme- and iron-mediated oxidative stress and sustained inflammatory reaction oxidatively modify DNA, lipids, and proteins, resulting in DNA hypermethylation, histone deacetylation or ER depletion [54]. Low ER expression may explain the reason for the poor prognosis of OCCC.

\section{Alterations of molecular events}

Some somatic mutations have been detected in paired eutopic and ectopic endometrium, and ectopic tissue has a higher mutation burden [55]. Endometriotic lesions commonly carry multiple somatic mutations; atypical endometriosis and co-existing tumors share nearly all of the somatic mutations, such as driver mutations in ARID1A, PIK3CA and high expression of MET and HNF1 $\beta$, and it is thought that those above mutations occurred early in the malignant transformation of the OCCC (Figure 3 \& 4, Table 1) .

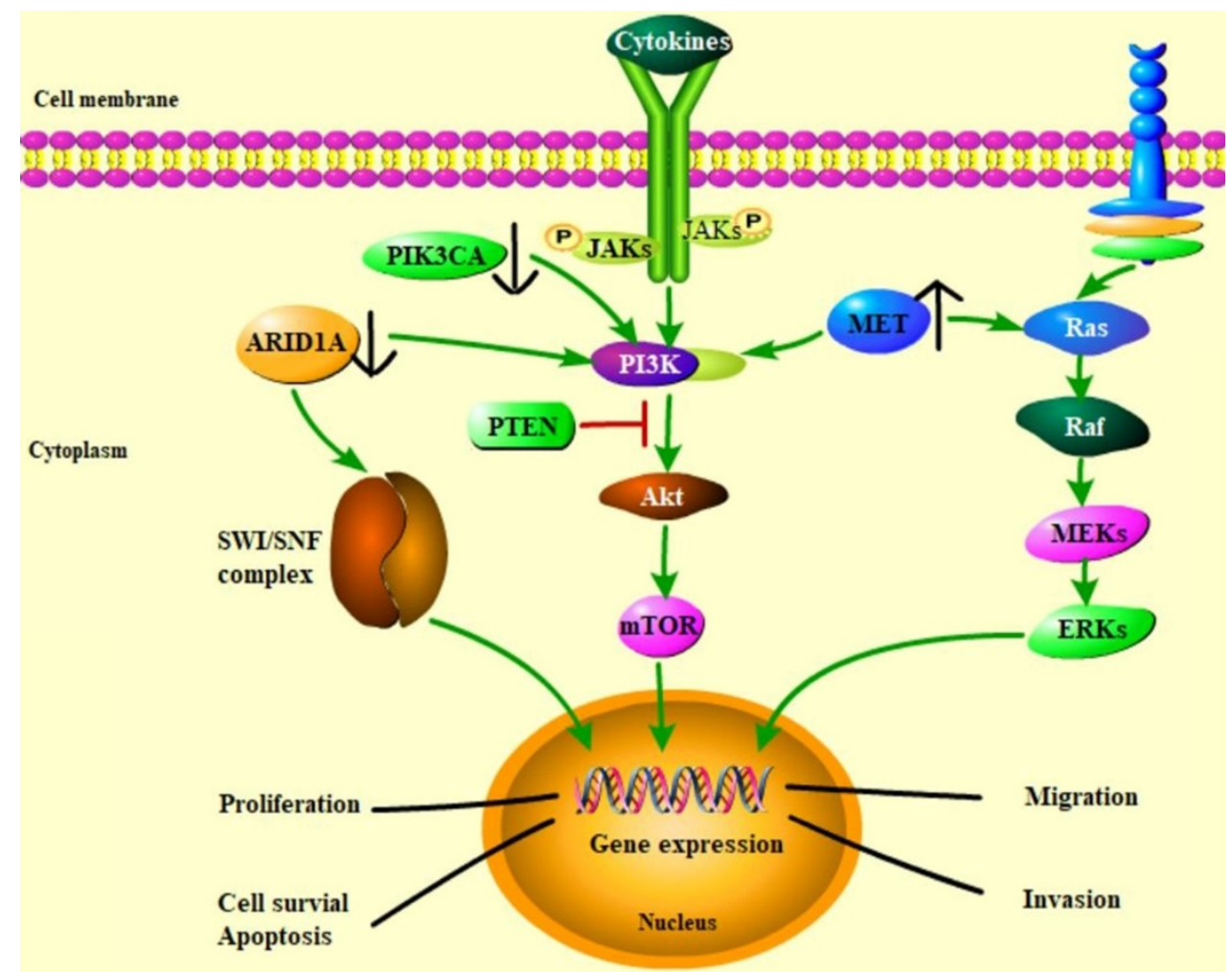

Figure 3. Alterations of several molecular events in endometriosis-associated OCCC. Genomic events frequently occurring in OCCC, such as ARIDIA, PIK3CA mutations, and MET overexpression, are possibly regulated by interacting pathways. 
Table 1. Critical genetic changes in endometriosis-associated OCCC

\begin{tabular}{|c|c|c|c|c|c|}
\hline Genes & Gene type & Change & Pathways affected & Roles in tumor development & References \\
\hline ARID1A & Tumor suppressor & Mutation in $46-57 \%$ & SWI/SNF complex; PI3K/AKT/mTOR & $\begin{array}{l}\text { Modulate accessibility of transcription } \\
\text { factors to promoters }\end{array}$ & {$[25,56-70]$} \\
\hline PIK3CA & Oncogenic & Mutation in $33-43 \%$ & $\mathrm{PI} 3 \mathrm{~K} / \mathrm{AKT} / \mathrm{mTOR}$ & Proliferation/survival & {$[36,73-83]$} \\
\hline MET & Oncogenic & Amplification in $24-37 \%$ & Ras/Raf/MEK/ERK; PI3K/AKT/mTOR & Proliferation/survival & [84-89] \\
\hline HNF-1 $\beta$ & & Over $95 \%$ positive & HNF-1 $\beta$ & Stimulation of transcription & {$[88,91-97]$} \\
\hline XRCC5 & & & & DNA repair & {$[52,114]$} \\
\hline PTCH2 & & & hedgehog signaling pathway & Proliferation/survival & {$[52,111]$} \\
\hline eEF1A2 & Oncogenic & & $\mathrm{PI} 3 \mathrm{~K} / \mathrm{AKT} / \mathrm{mTOR}$ & Apoptosis & {$[52,109,110]$} \\
\hline miR-191 & & & TIMP3 & Proliferation/invasion & {$[98,102]$} \\
\hline
\end{tabular}

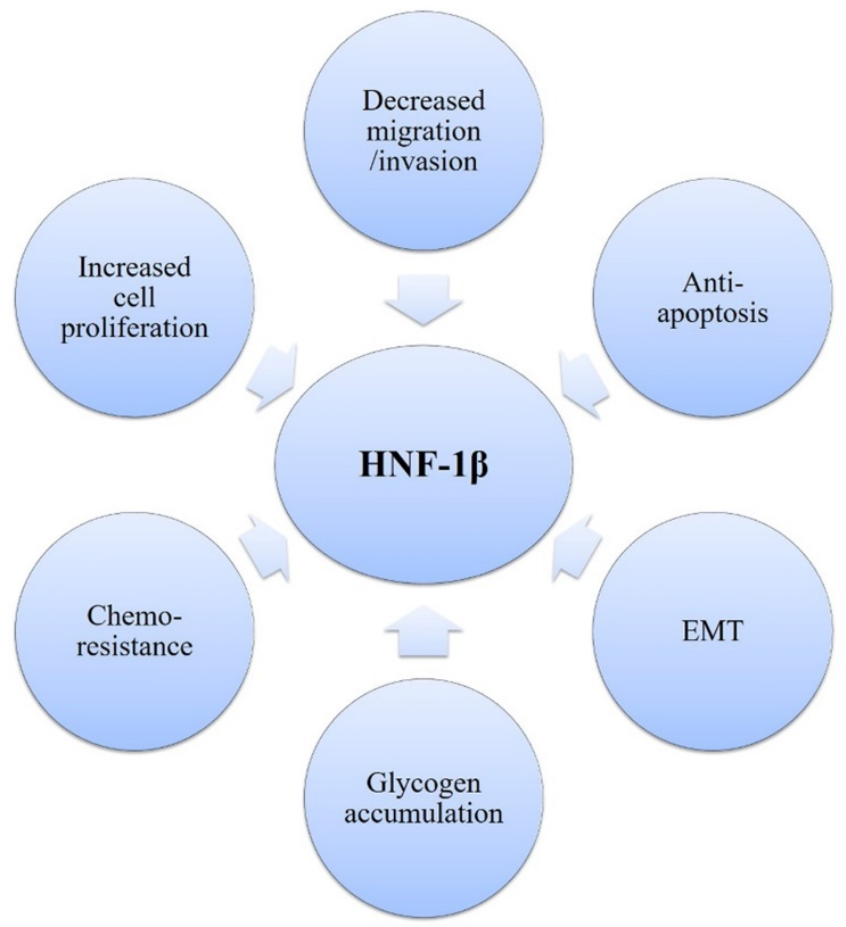

Figure 4. Pleiotropic role of HNF1 $\beta$ in establishing the OCCC phenotype.

\section{ARIDIA}

ARID1A (also known as BAF250a) is a ubiquitously expressed $250 \mathrm{kDa}$ protein that functions as part of the mammalian SWItch/Sucrose Fonfermentable Complex (SWI/SNF). This complex plays a major role in DNA repair either by promoting the accessibility of DNA on the chromatin directly or by improving the functions of DNA repair proteins, such as P53, GADD45, BRCA1 and Fanconi Anemia proteins indirectly [56]. By changing the accessibility of chromatin, it also regulates many cellular processes such as proliferation, differentiation, development and tumor suppression [56-58]. In 2010, ARID1A was first reported to be frequently mutated in OCCC. ARID1A mutations were found in 55 of 119 (46\%) OCCC using whole transcriptome sequencing in a report from the Canadian Ovarian Cancer Research tumor bank [25]. Simultaneously, a second report showed that ARID1A mutations could be detected in 24 of 42 (57\%) OCCC [59]. Additionally, these authors were able to show that, in two cases of OCCC with available adjacent atypical as well as distant endometriosis, identical ARID1A mutations were found in the cancer and the adjacent endometriosis but were absent in the distant endometriotic lesions, implying that ARID1A mutations play a role in the malignant transformation of endometriosis. A study including 54 patients demonstrated a progressive increase in ARID1A protein expression loss from normal endometrium ( $0 \%)$, to typical endometriosis $(19 \%)$, to atypical endometriosis (38\%), further supporting that ARID1A loss is an early event in OCCC pathogenesis [60]. ARID1A mutations or loss of protein expression have been reported in a wide range of gynecological and other malignancies over the past 3 years, firmly establishing ARID1A as a frequently mutated tumor-suppressor gene [61, 62].

Several studies have shown that ARID1A mutations are frequently in tumors that exhibit microsatellite instability (MSI) and often coexist with PIK3CA mutations. In Jones's study, 14 of 24 (58\%) tumors with ARID1A mutations also carried PIK3CA mutations, while 18 (17\%) had no mutations [59]. In agreement with previous results, $71 \%$ of tumors without ARID1A expression were found to have PIK3CA mutations compared to $44 \%$ of those with intact ARID1A expression in 42 OCCC patients [63]. The same pattern was also observed in uterine cancers with ARID1A mutations, which were enriched in a series of 222 cases of uterine cancer with PIK3CA and PTEN mutations [64]. In this series, ARID1A mutations were associated with phosphorylation of multiple members of phosphatidylinositol 3-kinase (PI3K), which means that ARID1A activates the PI3K pathway independent of PTEN and PIK3CA aberrations [64]. This is corroborated by subsequent studies which showed that loss of ARID1A expression usually coexisted with PI3K-AKT pathway activation [65]. AKT phosphorylation was increased in OCCC with ARID1A loss that was independent of the PTEN and PIK3CA status [66]. In addition, AKT phosphorylation in response to ARID1A knockdown has recently been reported in breast cancer and lung cancer cell lines $[67,68]$. 
The functional consequences of ARID1A loss in OCCC are unclear. Consistent with its proposed tumor suppressor effect, the re-expression of ARID1A in the OCCC cell line OVISE with ARID1A mutations resulted in growth inhibition [69]. Similarly, knockdown of ARID1A in the two IOSE cell lines led to increased proliferation in vitro and increased tumorigenicity when implanted subcutaneously in nude mice [69]. Recently reports has found that ARID1A knockdown promotes proliferation and regulates the cell cycle, especially G2/M checkpointrelated genes, such as AURKA, PLK1, PLK4, CCND1 and CCNB1 in mouse endometrium and human IOSE cell lines [70].

In summary, ARID1A loss appears to be a driving event in approximately half of OCCC cases. Clinically, there does not appear to be a distinct ARID1A-driven OCCC phenotype yet. Current research focuses on associating the ARID1A mutation with other mutations in OCCC and using them as prognostic factors for malignant tumors. In a study of OCCC, ARID1A mutations are related to platinumbased chemo-resistance, and these patients tend to have a shorter survival [71]. Although ARID1A mutation has not been considered as a prognostic factor for ovarian cancer, studies on breast cancer have shown that the lack of BAF250a is related to the low survival rate of postoperative disease, suggesting that it may be a breast cancer treatment target [72]. Once we have clearly demonstrated the mechanisms of malignant transformation caused by ARID1A mutations in OCCC, we can explore them to develop novel targeted therapies.

\section{PIK3CA}

Mutations in ARID1A are considered as an early event but inactivation of ARID1A alone is not enough to initiate the oncogenic transformation of either the endometrium or ovarian surface epithelium. Other mechanisms such as PIK3CA-activating mutations in cooperation with loss of ARID1A expression seem to be necessary to promoting the occurrence of OCCC [36]. Frequent PIK3CA mutations in OCCC were first reported in 2009 and further studie have confirmed an incidence of PIK3CA mutations in OCCC between 33 and $43 \%[73,74]$. The same mutations are also detected in the atypical endometriosis adjacent to OCCC but not in endometriosis distant from OCCC or solitary endometriosis, implying that they occur early in OCCC pathogenesis [75].

PIK3CA encodes a catalytic subunit of PI3K, mutations of which lead to increased kinase activity, in turn stimulating downstream AKT and increasing cell invasion and metastasis. Therefore, it plays a vital role in the occurrence and development of tumors, and are of great significance for clinical diagnosis, treatment and prognosis. Several studies have observed the activation of the PI3K/AKT pathway in endometriosis and OCCC [76]. PIK3CA mutations often occur simultaneously with ARID1A mutations, resulting in the $\mathrm{PI} 3 \mathrm{~K} / \mathrm{AKT}$ pathway activation in OCCC $[73,77]$. The PI3K/AKT pathway is the main regulator in cancer cell growth, proliferation, differentiation, motility, survival and glucose metabolism [78]. PI3K could regulate the progression of G1 cell cycle and the expression of cyclin by activating the AKT/mTOR /p70S6K1 signaling pathway in ovarian cancer cells. It could also promote cell survival via several ways, including phosphorylation and inactivation of the proapoptotic proteins Bad and caspase-9 [78, 79]. In addition, loss of ARID1A-encoded protein could influence pAKT activation, $\mathrm{\gamma H} 2 \mathrm{AX}$ alteration, and concomitant apoptosis pathway activation [80]. Moreover, activation of this pathway is strongly associated with a reduction in chemotherapy response in ovarian cancer [81]. With regards to outcomes, two series of 56 and 62 OCCC cases showed improved prognosis in OCCC patients with PIK3CA mutations [82, 83]. However, no differential activity of the PIK3CA inhibitors LY294002 and BEZ235 or the mTOR inhibitor temsirolimus was observed in a panel of OCCC cell lines with or without PIK3CA mutations [83]. Further research is needed to provide preliminary clinical evidence of benefit from targeting PIK3CA.

\section{MET}

As a proto-oncogene, MET encodes a receptor tyrosine kinase c-MET for hepatocyte growth factor (HGF), which appears to be the most frequently amplified gene in OCCC. MET overexpression and gene amplification are usually observed at a frequency of $22 \%$ and $24 \%-37 \%$ in OCCC, respectively $[84,85]$. Furthermore, in cases of endometriosis and adjacent OCCC components, the incidence of MET overexpression is gradually increasing. MET overexpression are observed at a frequency of $0 \%$ in the precursors of nonatypical form, $67 \%$ in atypical form, $92 \%$ in the relatively differentiated carcinoma components and $100 \%$ in the poorly differentiated carcinoma components, supporting the notion that MET is one of the key drivers of carcinogenesis [86]. When HGF binds with overexpressed MET, the Raf/Ras/mitogen-activated protein kinases (MAPK) pathway, the PI3K/AKT/mTOR signaling pathway and several other pathways are activated, thus stimulating the proliferation, migration, and invasion of cancer cells [87]. These results indicate that MET alterations may promote the development of the MET 
amplification-positive OCCC [86]. In addition, it has been reported that both MET overexpression and gene amplification are associated with adverse outcomes for OCCC patients [88, 89]. The survival rate of stage I and II OCCC patients with MET gene amplification is significantly lower compared to that of patients without MET gene amplification [84]. Knocking out MET expression by shRNA can increase cellular apoptosis and senescence and thus reduce the viability of OCCC cells [90]. Yamashita also observed AKT2 gene amplification in 5 of 21 samples (13 OCCC primary tumors and 8 OCCC cell lines) through arraybased comparative genomic hybridization analysis [90], suggesting that MET-amplified OCCC cells mainly depend on the MET/PI3K/AKT pathway activation to regulate cell proliferation and survival. Targeted drugs that inhibit the MET/PI3K/AKT pathway are expected to be used in the clinical treatment of OCCC.

\section{HNF-1 $\beta$}

HNF-1 $\beta$ is a transcription factor, which is involved in embryonic development and tissue-specific gene expression in multiple organs, including the ovaries. In 2003, it was first reported that nuclear IHC staining for HNF-1 $\beta$ was positive in 20 of 21 OCCC cases compared with only 1 of 61 non-OCCC EOC [88]. Subsequent reports have confirmed that over $95 \%$ of OCCC stain positive for HNF-1 $\beta$, whereas other EOC subtypes do so extremely rarely [91]. Furthermore, in a series of 12 OCCC cases with available adjacent endometriosis, nine showed positive staining for HNF-1 $\beta$ in the nonmalignant endometriotic epithelium, and 16 of 40 benign endometriotic cysts also showed HNF-1 $\beta$ positivity [91]. Expression of HNF-1 $\beta$ was identified in endometriosis, atypical endometriosis and OCCC, implying a shared molecular pathogenesis. Early differentiation to the clear cell lineage primarily occurs in ovarian endometriosis, which may explain why OCCC frequently occurs in ovarian endometriosis [91].

As OCCC is characterized by HNF-1 $\beta$ overexpression, HNF-1 $\beta$ is a useful molecular marker that could help diagnose OCCC [91, 92]. The hypomethylation of HNF-1 $\beta$ CpG island participates in upregulation of HNF-1 $\beta$ in OCCC [93]. Previous studies have demonstrated that $\mathrm{HNF}-1 \beta$ regulates the gene/protein expression such as annexin A4, osteopontin, uridine diphosphate (UDP)glucuronosyl transferase 1A1 (UGT1A1), and insulinlike growth factor-binding protein 1 (IGFBP-1), which are vital for cancer progression [88]. Many biological functions of OCCC also depend on HNF-1 $\beta$ and are possibly regulated by interacting pathways (Figure 4).
HNF-1 $\beta$ is critical for cell survival in endometriosis and OCCC and involves the features of OCCC, including glycogen accumulation in cancer cells, strong anti-apoptotic activity and chemo-resistance due to lower cell proliferation [88]. First, HNF-1 $\beta$ could promote glucose uptake and glycolysis, contributing to cell survival under hypoxic conditions or stressful environments. Moreover, HNF-1 $\beta$ overexpression leads to detoxification to overcome persistent inflammation and oxidative stress, which are required for carcinogenesis of endometriosis. HNF-1 $\beta$ also plays an essential role in the anti-apoptosis of OCCC. Reduction of HNF-1 $\beta$ mRNA induced apoptosis of OCCC cells [88]. Upregulation of HNF-1 $\beta$ by NF-kB regulates the susceptibility to apoptosis via altering bcl-2 expression in OCCC [94].

Moreover, HNF-1 $\beta$ appears to be one of the main drivers of gene expression programs in OCCC. The gene expression profiling study reported a significant overlap between their 25-gene HNF-1 $\beta$ signature, derived from overexpression in kidney HEK293 cells, and previously reported OCCC expression profiles $[88,95]$. Gene expression signatures derived from HNF-1 $\beta$ knockdown in EOC RMG-I and RMG-II cell lines could distinguish OCCC cases from other EOCs in two publicly available ovarian cancer datasets [96]. In addition, HNF-1 $\beta$ was shown to drive gene expression profiles similar to the epithelialmesenchymal transition (EMT) in SKOV3 cells, leading the authors to conclude that HNF-1 $\beta$ is important for maintaining the E-cadherin-expressing epithelial phenotype in OCCC [97].

In summary, HNF-1 $\beta$ overexpression is a defining characteristic of OCCC, driving geneexpression signatures and having a major impact on OCCC proliferation, apoptosis and metabolic profiles. However, no specific inhibitors of HNF-1 $\beta$ have yet been developed, and the potential of HNF-1 $\beta$ as a new therapeutic target must be supported by further studies.

\section{MiRNAs}

It has been discovered that new regulators of gene expression, miRNAs, may be involved in the transformation of endometriosis into OCCC $[98,99]$. MiRNAs have been implicated to play an important role in different pathological and physiological processes, such as cell proliferation, apoptosis, hypoxia, inflammation, angiogenesis, extracellular matrix remodeling, and tissue repair, and their dysregulation points to various pathologies, including endometriosis and EAOC. However, which miRNA is actually related to EAOC remains controversial. MiR-21 and miR-214 are significantly upregulated in EAOC and can suppress the expression of PTEN 
[100]. As a well-known tumor suppressor gene, PTEN inactivation is an early event in the malignant transformation of endometriosis [101]. Another miRNA significantly upregulated in endometriosis and EAOC patients compared with healthy controls is miR-191 [98]. Dong found that miR-191 could directly regulate TIMP3 expression in both endometriosis and EAOC cells [102]. TIMP3 is a member of the metalloproteinase family and may be a key factor regulating cell proliferation and invasion of endometriosis and EAOC cells. Through modulating TIMP3, miR-191 could also promote cell proliferation and invasion of endometriosis cells. The miR-191-TIMP3 axis might take an important part in the pathological development of endometriosis to EAOC. Further studies indicated that miR-30a, miR-30c, miR-31, miR-486-5p, miR-532-5p, and miR-885-5p were also increased in OCCC. MiR-30 was five-fold overexpressed in OCCC [103]. Sestito showed that miR-30a overexpression delayed tumor formation in xenograft tumors, and made ovarian cancer cells sensitive to chemotherapy [104]. The expression of miR-486-5p in serum and ascites samples from EAOC patients was higher compared to that from ovarian endometrioma patients. Upregulation of miR-486-5p significantly increased cell proliferation and migration, which might act as an oncogenic miRNA in EAOC [105]. Overexpression of miR-532 inhibited ovarian cancer cell proliferation, invasion and tumor growth, while miR-532 downregulation was correlated with poor survival in ovarian cancer patients [106]. Compared to eutopic endometrium, miR-126 was significantly decreased in endometriosis, which induced the proliferation, migration, and invasion of non-ovarian cancer cells through PI3K, KRAS, or VEGF [107]. Additionally, although ovarian cancer patients were not included in the research, reduced miR-126 level was an essential predictor of poor survival in cancer patients [108]. Thus, miRNAs may be useful tools in detecting OCCC, but further research should be conducted to validate the possibility.

\section{Others}

A recent study compared various molecular changes in endometriosis-associated OCCC through immunohistochemistry. Five novel biomarkers, eEF1A2, PTCH2, PPP1R14B, PPP2R1A, and XRCC5 are strongly overexpressed in OCCC and associated endometriosis but not in benign endometriosis [52]. The tissue-specific translation elongation factor eEF1A2 has been viewed as a potential oncogene, overexpression of which is associated with OCCC. The protein elongation network can activate tumorigenesis and inhibit apoptosis [109]. Chang also showed that eEF1A2 could interact with peroxiredoxin $1(\operatorname{Prdx} 1)$ to provide cells with strong resistance to oxidative stress-induced cell death [110]. PTCH2 modulates tumorigenesis and is involved in hedgehog signaling, the activation of which is essential for cell proliferation [111]. PPP1R14B, as an inhibitor of protein-phosphatase 1, is necessary for cell migration and retraction [112]. Mutations in PPP2R1A, a subunit of the serine-threonine phosphatase PP2A that acts as a tumor suppressor by dephosphorylating oncogenes were initially reported to occur in $7 \%$ of OCCC [59]. A subsequent report confirmed their presence in $4 \%$ of OCCC but their functional effects in OCCC are, at present, unknown [113]. XRCC5 is a subunit of Ku ATP-dependent DNA helicase heterodimer, used to repair double-stranded DNA breaks. Compared to endometriosis without cancer, XRCC5 was overexpressed in OCCC associated with endometriosis [52]. Recent investigations have demonstrated that increased levels of double-strand DNA break repair proteins such as XRCC5 protect ovarian cancer cells from apoptosis induced by genotoxic stress, which may be related to chemo-sensitivity [114]. These new proteins may play a role in the pathogenesis of endometriosisassociated OCCC and will be studied in the future.

\section{Stem cells}

Many reports indicate that OCCC is rich in a subset of cancer stem cells, and ovarian cancer stem-like cells could be isolated from OCCC cells [115, 116]. None of the current theories about endometriosis clearly explained them. Some recent proposals have suggested that H3K27me3 histone modification involve the process. A large enrichment of H3K27me3 histone-modified gene set was observed in endometriotic cells but it was silent in OCCC [52]. H3K27me3 is marker for gene silencing through polycomb group (PcG) complexes [117]. These target gene sets were silent in embryonic stem cells and pluripotent cells, but expressed in specific lineages of normal differentiated cells [118-120]. A somatic cell reprogramming study has demonstrated that H3K27me3 silencing marker was increased during the cell transition to a pluripotent state [121]. The PcG-regulated gene sets need to remain repressed to maintain pluripotency and be ready to be activated during lineage cell differentiation [119]. As a mesenchyme maintenance regulator, WT1 was found in these gene sets, which plays a vital role in tissue repair and regeneration [122]. Immunohistochemistry confirmed the result that the expression of WT1 was increased in endometriosis compared with OCCC. Therefore, these lineage-specific genes are expressed in endometriosis, while are silenced in OCCC, 
suggesting that epigenetic reprogramming mechanisms convert differentiated endometriotic cells into pluripotency in OCCC. There are two points worth further study in the process. First, the gene sets regulated by PcG were silenced in ER-negative breast tumors, which was similar to ER-negative OCCC [118]. Estrogen signaling may affect the function of PcG. Second, an epigenetic antagonism was observed between polycomb and SWI/SNF complexes in the process of stem cell programming and tumorigenesis [123]. ARID1A is exactly a subunit of the SWI/SNF complex and often loses its function in OCCC. However, research in this area does not provide any direct evidence, it is obviously premature to directly target stem cells as a therapeutic tool.

\section{Clinical features relative to endometriosis-associated OCCC}

Endometriosis-associated OCCC seems a special entity whose clinical features are different from other histological types. The currently recognized dual model of Kurman and Shih on the pathogenesis of epithelial ovarian cancer proposes that endometriosis associated ovarian cancer such as low-grade serous, low-grade endometrioid, and clear cell carcinoma usually belong to Type I tumors [124]. There are no studies to report the difference between the above three. A comparison of the clinical features of OCCC and ovarian high-grade serous carcinoma is summarized in Table 2. OCCC is more common among Asians. The incidence of OCCC is 3.1\%-11.1\% in the United States, versus $25 \%-30 \%$ in Japan and $10.3 \% \sim 11.6 \%$ in Korea [12-14]. The OCCC patients are often diagnosed at a younger age about 55 years old. Patients with pathologically confirmed endometriosis-associated OCCC are 4 to 8 years younger at diagnosis than those without endometriosis [125]. OCCC tends to appear at significantly earlier stages, possibly due to slow tumor growth and frequent presentation of large tumor pelvic masses [126]. OCCC has a higher proportion of early-stage tumors compared to serous cancer, and about $60 \%$ of OCCC patients have stage I disease [127]. The prevalence of vascular thrombotic events in this disease is also increased [127]. About $16.4 \%$ of Japanese patients have venous thrombosis. The prevalence of vascular thrombotic events is up to $40 \%$, twice as high as epithelial ovarian cancer.

Most patients with endometriosis-associated OCCC have a history of endometriosis. If patients with endometriosis have the following conditions, the possibility of malignancy should be highly considered: (1) early diagnosed or long-standing endometriosis, (2) larger size of pelvic mass (diameter $\geq 9 \mathrm{~cm}$ ), (3) a rapid increase of mass in a short period,
(4) short-term recurrences after treatment, and (5) postmenopausal status at the time of the diagnosis [128-134]. Through a long period follow-up, Varma found an average year for malignant transformation of endometriosis to ovarian cancer was more than 8 years [135]. Dyspareunia and dysmenorrhea are more frequently observed in patients with endometriosisassociated OCCC. Women with endometriosis may seek medical help for their symptoms and find that they have ovarian cancer by accident, whereas patients without endometriosis may develop symptoms only at later stages, which explains why most EAOC patients are diagnosed earlier. Moreover, endometriosis-associated OCCC patients are more susceptible to infertility. Brinton found that the incidence of ovarian cancer in infertile women with endometriosis is higher than those without endometriosis [136]. Stewart further pointed out that the ovarian cancer risk is reduced among women with endometriosis who have children [137].

Table 2. Clinical comparison of OCCC and ovarian high-grade serous carcinoma

\begin{tabular}{ll}
\hline OCCC & Ovarian high-grade serous carcinoma \\
\hline Common in Asia & Common in Europe and America \\
More common in young patients & More common in elderly patients \\
More common in the early stage & $\begin{array}{l}\text { More common in the late stage (III-IV: } \\
\text { (I-II: 7-81\%) }\end{array}$ \\
Associated with endometriosis & $\begin{array}{l}\text { Associated with fallopian tube } \\
\text { intraepithelial cancer }\end{array}$ \\
Resistant to first-line & Sensitive to first-line chemotherapy \\
chemotherapy & ER/PR staining positive (65-96\%) \\
ER/PR staining negative & HNF-1 $\beta$ (-) \\
HNF-1 $\beta$ (+) (over 95\%) & No ARID1A mutations \\
High ARID1A mutations (46-57\%) & Rare PIK3CA mutations \\
High PIK3CA mutations (33-43\%) &
\end{tabular}

The prognosis of early-stage OCCC is obviously superior to advanced OCCC. The 5-year overall survival (OS) and progression-free survival (PFS) rates are $80 \% \sim 89 \%$ and $56 \% \sim 88 \%$ for International Federation of Gynecology and Obstetrics (FIGO) stages I and II and decrease to $52 \%$ and $25 \%$ for stages III and IV, respectively[138, 139]. Among patients at early-stage, survival is better in OCCC compared to serous adenocarcinoma. However, OCCC patients at late stage tended to have poorer prognosis than those with other histological subtypes of EOC, especially in advanced EOC stages with 1.65-fold higher hazard rate for death $[12,140]$. Several studies also indicated patients with endometriosis-associated OCCC had a better prognosis than non-endometriosis associated group which may be explained endometriosisassociated OCCC was more likely to be first diagnosis at younger age, lower stages and poor aggressiveness. Kumar retrospectively compared 42 cases of EAOC with 184 cases of non-endometriosis associated 
ovarian carcinoma (non-EAOC) and reported that the median survival (199 vs 62 months) and the 5 year survival $(62 \%$ vs $51 \%)$ of EAOC was better than non-EAOC [126]. Association with endometriosis may be a crucial predictor of better survival in ovarian cancer.

\section{Prevention of endometriosis-associated OCCC}

Clinicians should be aware of the increased risk of endometriosis-associated OCCC in high-risk populations and select appropriate preventive measures. Long-term use of oral contraceptives is a promising strategy to prevent ovarian cancer. Studies on the relationship between oral contraceptives and ovarian cancer indicate reduced ovarian cancer risk with oral contraceptive use [141]. Two recent large studies have focused on the effects of tubal ligation in decreasing the risk of ovarian cancer [142]. This risk reduction was the greatest for clear-cell and endometrioid carcinoma [143]. Tubal ligation has a protective effect on these two subtypes of ovarian cancer, which is believed to be related to the prevention of retrograde menstruation, ovarian seeding by endometrial cells, and inflammation. Evidence suggests that oophorectomy reduces ovarian cancer risk effectively. Investigators have generally reported that unilateral oophorectomy and radical extirpation of all visible endometriosis following an endometriosis diagnosis have a good protective effect on the subsequent development of ovarian cancer [144]. The ovarian cancer risk increases with the age at which ovarian endometriosis is diagnosed, and this increased risk is more significant in women aged $\geq 50$ years [145]. Based on these data, active surgical intervention should be considered for older women suffering from endometriosis.

\section{Conclusions}

Patients with endometriosis have a higher risk of developing OCCC is compelling. OCCC is a specific pathological type of EOC with unique molecular and clinical features. We have reported a variety of molecular events such as ARID1A mutations, PIK3CA mutations, MET activation, HNF-1 $\beta$ activation, and miRNA dysfunction in endometriosis-associated OCCC. Besides, micro-environmental factors such as oxidative stress, immune cell dysfunction, inflammation, steroid hormones, and stem cells also play crucial roles in the carcinogenesis. Endometriosis-associated OCCC seems to be a special entity that differ from those of other histological types. OCCC is chemoresistant, has a poor prognosis, and is often difficult to treat. To improve the survival of OCCC patients, it is urgent to develop novel treatments based on its molecular alterations. The ARID1A, PI3K/AKT/mTOR, MET, and HNF-1 $\beta$ pathways are frequently activated and are considered promising targets for the treatment of endometriosisassociated OCCC. Some targeted inhibitors for these pathways are currently undergoing preclinical trials to evaluate whether they can be used as a treatment strategy for endometriosis-associated OCCC. The feasibility and efficiency of new target drugs in patients with endometriosis-associated OCCC should also be studied in future clinical trials.

\section{Acknowledgements}

This work was supported by grants from the National Natural Science Foundation of China (grant number 81472761 to G.L.).

\section{Competing Interests}

The authors have declared that no competing interest exists.

\section{References}

1. Mandai $\mathrm{M}$, Yamaguchi $\mathrm{K}$, Matsumura $\mathrm{N}$, et al. Ovarian cancer in endometriosis: molecular biology, pathology, and clinical management. Int J Clin Oncol. 2009; 14: 383-91.

2. Brinton LA, Gridley G, Persson I, et al. Cancer risk after a hospital discharge diagnosis of endometriosis. Am J Obstet Gynecol. 1997; 176: 572-9.

3. Kim HS, Kim TH, Chung $\mathrm{HH}$, et al. Risk and prognosis of ovarian cancer in women with endometriosis: a meta-analysis. Brit J Cancer. 2014; 110: 1878-90.

4. Murakami K, Kotani Y, Shiro R, et al. Endometriosis-associated ovarian cancer occurs early during follow-up of endometrial cysts. Int J Clin Oncol. 2020; 25: 51-8.

5. Barreta A, Sarian LO, Ferracini AC, et al. Endometriosis-Associated Ovarian Cancer: Population Characteristics and Prognosis. Int J Gynecol Cancer. 2018; 28: 1251-7.

6. Itamochi H, Kigawa J, Terakawa N. Mechanisms of chemoresistance and poor prognosis in ovarian clear cell carcinoma. Cancer Sci. 2010; 99: 653-8.

7. Marks EI, Brown VS, Dizon DS. Genomic and Molecular Abnormalities in Gynecologic Clear Cell Carcinoma. Am J Clin Oncol. 2020; 43: 139-45.

8. Wilbur MA, Shih I-M, Segars JH, et al. Cancer Implications for Patients with Endometriosis. Semin Reprod Med. 2017; 35: 110-6.

9. Bamias A, Psaltopoulou T, Sotiropoulou M, et al. Mucinous but not clear cell histology is associated with inferior survival in patients with advanced stage ovarian carcinoma treated with platinum-paclitaxel chemotherapy. Cancer. 2010; 116: 1462-8.

10. Scully RE, Sobin LH. Histologic typing of ovarian tumors. Arch Pathol Lab Med. 1987; 111: 794.

11. Anglesio MS, Carey MS, Köbel M, et al. Clear cell carcinoma of the ovary: a report from the first Ovarian Clear Cell Symposium, June 24th, 2010. Gynecol Oncol. 2011; 121: 407-15.

12. Oliver KE, Brady WE, Birrer $\mathrm{M}$, et al. An evaluation of progression free survival and overall survival of ovarian cancer patients with clear cell carcinoma versus serous carcinoma treated with platinum therapy: An NRG Oncology/Gynecologic Oncology Group experience. Gynecol Oncol. 2017; 147: 243-9.

13. Kim SI, Lim MC, Lim J, et al. Incidence of epithelial ovarian cancer according to histologic subtypes in Korea, 1999 to 2012. J Gynecol Oncol. 2016; 27: 187-92.

14. Okamoto A, Glasspool RM, Mabuchi S, et al. Gynecologic Cancer InterGroup (GCIG) consensus review for clear cell carcinoma of the ovary. Int J Gynecol Cancer. 2014; 24 (9 Suppl 3): S20-5.

15. Sampson JA. Endometrial Carcinoma of The Ovary, Arising in Endometrial Tissue in That Organ. Am J Obstet Gynecol. 1925; 9: 111-4.

16. Brinton LA, Gridley G, Persson I, et al. Cancer risk after hospital discharge diagnosis of endometriosis. Am J Obstet Gynecol. 1997; 176: 572-9.

17. Pearce C, Templeman C, Rossing MA, et al. Association between endometriosis and risk of histological subtypes of ovarian cancer: a pooled analysis of case-control studies. Lancet Oncol. 2012; 13: 385-94.

18. Mogensen JB, Kjær SK, Mellemkjær L, et al. Endometriosis and risks for ovarian, endometrial and breast cancers: A nationwide cohort study. Gynecol Oncol. 2016; 143: 87-92.

19. Hermens M, Altena AM, Nieboer TE, et al. Incidence of endometrioid and clear-cell ovarian cancer in histological proven endometriosis: the ENOCA 
population-based cohort study - ScienceDirect. Am J Obstet Gynecol. 2020; 223: 107.e1-.e11.

20. Scott RB. Malignant changes in endometriosis. Obstet Gynecol. 1953; 2: 283-9.

21. Lagrenade A, Silverberg SG. Ovarian tumors associated with atypical endometriosis. Hum Pathol. 1988; 19: 1080-4.

22. Ogawa S, Kaku T, Amada S, et al. Ovarian Endometriosis Associated with Ovarian Carcinoma: A Clinicopathological and Immunohistochemical Study. Gynecol Oncol. 2000; 77: 298-304.

23. Fukunaga $M$, Nomura K, Ishikawa E, et al. Ovarian atypical endometriosis: its close association with malignant epithelial tumours. Histopathology. 1997; 30: 249-55.

24. Siufi Neto J, Kho RM, Siufi DF, et al. Cellular, Histologic, and Molecular Changes Associated With Endometriosis and Ovarian Cancer. J Minim Invasive Gynecol. 2014; 21: 55-63.

25. Wiegand $\mathrm{KC}$, Shah SP, Al-Agha OM, et al. ARID1A mutations in endometriosis-associated ovarian carcinomas. N Engl J Med. 2010; 363: 1532-43.

26. Chunpeng W, Zhenzhen L, Xin L, et al. The Association between Endometriosis, Tubal Ligation, Hysterectomy and Epithelial Ovarian Cancer: Meta-Analyses. Int J Environ Res Public Health. 2016; 13: 1138.

27. Klemmt PAB, Starzinski-Powitz A. Molecular and Cellular Pathogenesis of Endometriosis. Curr Womens Health Rev. 2018; 14: 106-16.

28. King CM, Barbara C, Prentice A, et al. Models of endometriosis and their utility in studying progression to ovarian clear cell carcinoma. J Pathol. 2016; 238: $185-96$.

29. Takeshi H. Repair System of 7, 8-Dihydro-8-Oxoguanine as a Defense Line against Carcinogenesis. J Radiat Res. 2008; 49: 329-40.

30. Yamaguchi K, Mandai M, Toyokuni S, et al. Contents of Endometriotic Cysts, Especially the High Concentration of Free Iron, Are a Possible Cause of Carcinogenesis in the Cysts through the Iron-Induced Persistent Oxidative Stress. Clin Cancer Res. 2008; 14: 32-40.

31. Hsu JY, Reimann JDR, Sørensen CS, et al. E2F-dependent accumulation of hEmi1 regulates S phase entry by inhibiting APC(Cdh1). Nat Cell Biol. 2002; 4: 358-66.

32. Gütgemann I, Lehman NL, Jackson PK, et al. Emi1 protein accumulation implicates misregulation of the anaphase promoting complex/cyclosome pathway in ovarian clear cell carcinoma. Modern Pathol. 2008; 21: 445-54.

33. Winarto H, Tan M, Sadikin M, et al. ARID1A Expression is Down-Regulated by Oxidative Stress in Endometriosis and Endometriosis-Associated Ovarian Cancer. Transl Oncogenomics. 2017; 9: 1177272716689818.

34. Kajihara H, Yamada Y, Kanayama S, et al. Clear cell carcinoma of the ovary: potential pathogenic mechanisms (Review). Oncol Rep. 2010; 23: 1193-203.

35. Riccio LDGC, Santulli $P$, Marcellin L, et al. Immunology of endometriosis. Best Pract Res Cl Ob. 2018; 50: 39-49.

36. Chandler RL, Damrauer JS, Raab JR, et al. Coexistent ARID1A-PIK3CA mutations promote ovarian clear-cell tumorigenesis through pro-tumorigenic inflammatory cytokine signalling. Nat Commun. 2015; 6: 6118.

37. Laganà AS, Triolo O, Salmeri FM, et al. Natural Killer T cell subsets in eutopic and ectopic endometrium: a fresh look to a busy corner. Arch Gynecol Obstet. 2016; 293: 941-9

38. Hanada T, Tsuji $\mathrm{S}$, Nakayama $\mathrm{M}$, et al. Suppressive regulatory $\mathrm{T}$ cells and latent transforming growth factor- $\beta$-expressing macrophages are altered in the peritoneal fluid of patients with endometriosis. Reprod Biol Endocrinol. 2018; 16: 9.

39. Salmeri FM, Lagana`AS, Vincenza S, et al. Behavior of Tumor Necrosis Factoralpha and Tumor Necrosis Factor Receptor I/Tumor Necrosis Factor Receptor 2 System in Mononuclear Cells Recovered From Peritoneal Fluid of Women With Endometriosis at Different Stages. Reprod Sci. 2015; 22: 165-72.

40. Sturlese E, Salmeri FM, Retto G, et al. Dysregulation of the Fas/FasL system in mononuclear cells recovered from peritoneal fluid of women with endometriosis. J Reprod Immunol. 2011; 92: 74-81.

41. Vetvicka V, Laganà AS, Salmeri FM, et al. Regulation of apoptotic pathways during endometriosis: from the molecular basis to the future perspectives. Arch Gynecol Obstet. 2016; 294: 897-904.

42. Hyun AS, Monsanto SP, Caragh $\mathrm{M}$, et al. Pathophysiology and Immune Dysfunction in Endometriosis. Biomed Res Int. 2015; 2015: 795976.

43. Izumi G, Koga K, Takamura M, et al. Involvement of immune cells in the pathogenesis of endometriosis. J Obstet Gynaecol Res. 2018; 44: 191-8.

44. Polak G, Barczyński B, Bednarek W, et al. Increased levels of proteins of the acute inflammatory phase in the peritoneal fluid of women with advanced stages of endometriosis. Ginekol Pol. 2015; 86: 414-8.

45. Malutan AM, Tudor D, Nicolae C, et al. Pro-inflammatory cytokines for evaluation of inflammatory status in endometriosis. Cent Eur J Immunol. 2015; 1: 96-102.

46. Edwards RP, Huang X, Vlad AM. Chronic inflammation in endometriosis and endometriosis-associated ovarian cancer: New roles for the "old" complement pathway. Oncoimmunology. 2015; 4: e1002732.

47. Suryawanshi S, Huang X, Elishaev E, et al. Complement Pathway Is Frequently Altered in Endometriosis and Endometriosis-Associated Ovarian Cancer. Clin Cancer Res. 2014; 20: 6163-74

48. Nunez-Cruz S, Gimotty PA, Guerra MW, et al. Genetic and pharmacologic inhibition of complement impairs endothelial cell function and ablates ovarian cancer neovascularization. Neoplasia. 2012; 14: 994-1004.

49. Rutkowski MJ, Sughrue ME, Kane AJ, et al. The complement cascade as a mediator of tissue growth and regeneration. Inflamm Res. 2010; 59: 897-905.
50. Markiewski MM, Deangelis RA, Benencia F, et al. Modulation of the anti-tumor immune response by complement. Nat Immunol. 2008; 9: 1225-35.

51. Su KM, Lin TW, Liu LC, et al. The Potential Role of Complement System in the Progression of Ovarian Clear Cell Carcinoma Inferred from the Gene Ontology-Based Immunofunctionome Analysis. Int J Mol Sci. 2020; 21: 2824.

52. Worley MJ, Liu S, Hua Y, et al. Molecular Changes in Endometriosis-Associated Ovarian Clear Cell Carcinoma. Eur J Cancer. 2015; 51: 1831-42.

53. Haidarali E, Vahedi A, Mohajeri S, et al. Evaluation of the Pathogenesis of Tumor Development from Endometriosis by Estrogen Receptor, P53 and Bcl-2 Immunohistochemical Staining. Asian Pac J Cancer Prev. 2016; 17: 5247-50.

54. Yasuhito T, Yoshihiko Y, Hiroshi S, et al. Modulation of estrogenic action in clear cell carcinoma of the ovary (Review). Exp Ther Med. 2012; 3: 18-24.

55. Li X, Zhang Y, Zhao L, et al. Whole-exome sequencing of endometriosis identifies frequent alterations in genes involved in cell adhesion and chromatin-remodeling complexes. Hum Mol Genet. 2014; 23: 6008-21.

56. Reisman D, Glaros S, Thompson EA. The SWI/SNF complex and cancer. Oncogene. 2009; 28: 1653-68.

57. Ruderman R, Pavone ME. Ovarian cancer in endometriosis. Clinical and molecular aspects: an update. Minerva Ginecol. 2017; 69: 286-94.

58. Mao TL, Ardighieri L, Ayhan A, et al. Loss of ARID1A expression correlates with stages of tumor progression in uterine endometrioid carcinoma. Am J Surg Pathol. 2013; 37: 1342-8.

59. Jones S, Wang TL, Shih IM, et al. Frequent mutations of chromatin remodeling gene ARID1A in ovarian clear cell carcinoma. Science. 2010; 330: 228-31.

60. Xiao W, Awadallah A, Wei X. Loss of ARID1A/BAF250a expression in ovarian endometriosis and clear cell carcinoma. Int J Clin Exp Pathol. 2012; 5: $642-50$.

61. Wiegand KC, Lee AF, Al-Agha OM, et al. Loss of BAF250a (ARID1A) is frequent in high-grade endometrial carcinomas. J Pathol. 2011; 224: 328-33.

62. Wu JN, Roberts C. ARID1A Mutations in Cancer: Another Epigenetic Tumor Suppressor? Cancer Discov. 2013; 3: 35-43.

63. Yamamoto S, Tsuda H, Takano M, et al. Loss of ARID1A protein expression occurs as an early event in ovarian clear-cell carcinoma development and frequently coexists with PIK3CA mutations. Mod Pathol. 2012; 25: 615-24.

64. Liang $\mathrm{H}$, Cheung $\mathrm{L}$, Li J, et al. Whole-exome sequencing combined with functional genomics reveals novel candidate driver cancer genes in endometrial cancer. Genome Res. 2012; 22: 2120-9.

65. Huang HN, Lin MC, Huang WC, et al. Loss of ARID1A expression and its relationship with PI3K-Akt pathway alterations and ZNF217 amplification in ovarian clear cell carcinoma. Mod Pathol. 2014; 27: 983-90.

66. Wiegand KC, Hennessy BT, Leung S, et al. A functional proteogenomic analysis of endometrioid and clear cell carcinomas using reverse phase protein array and mutation analysis: protein expression is histotype-specific and loss of ARID1A/BAF250a is associated with AKT phosphorylation. BMC Cancer. 2014; 14: 120.

67. Berns K, Gennissen A, Hijmans EM, et al. Loss of ARID1A confers resistance to multiple targeted cancer drugs through activation of AKT signaling. Eur J Cancer. 2013; 49(Suppl3): S16-S17.

68. Zhang $\mathrm{Y}, \mathrm{Xu} \mathrm{X}$, Zhang M, et al. ARID1A is downregulated in non-small cell lung cancer and regulates cell proliferation and apoptosis. Tumor Biol. 2014; 35. 5701-7.

69. Guan B, Wang TL, Iem S. ARID1A, a Factor That Promotes Formation of SWI/SNF-Mediated Chromatin Remodeling, Is a Tumor Suppressor in Gynecologic Cancers. Cancer Res. 2011; 71: 6718-27.

70. Gounaris I, Brenton J. ARID1A role in cell cycle regulation and proliferation in mouse and human gynaecological tissues reveals potential therapeutic targets. Ann Oncol. 2014; 25: iv53-iv.

71. Katagiri A, Nakayama K, Rahman MT, et al. Loss of ARID1A expression is related to shorter progression-free survival and chemoresistance in ovarian clear cell carcinoma. Mod Pathol. 2012; 25: 282-8.

72. Zhao J, Liu C, Zhao Z. ARID1A: a potential prognostic factor for breast cancer. Tumor Biol. 2014; 35: 4813-9.

73. Kuo KT, Mao TL, Jones S, et al. Frequent Activating Mutations of PIK3CA in Ovarian Clear Cell Carcinoma. Am J Pathol. 2009; 174: 1597-601.

74. Yamamoto S, Tsuda $\mathrm{H}$, Takano $\mathrm{M}$, et al. PIK3CA mutation is an early event in the development of endometriosis-associated ovarian clear cell adenocarcinoma. J Pathol. 2011; 225: 189-94.

75. Samartzis EP, Samartzis N, Noske A, et al. Loss of ARID1A/BAF250aexpression in endometriosis: a biomarker for risk of carcinogenic transformation? Mod Pathol. 2012; 25: 885-92.

76. Xunqin Y, Ellen PM, Zhenxiao L, et al. Increased activation of the PI3K/AKT pathway compromises decidualization of stromal cells from endometriosis. J Clin Endocrinol Metab. 2012; 97: E35-43.

77. Samartzis E, Noske A, Dedes K, et al. ARID1A Mutations and PI3K/AKT Pathway Alterations in Endometriosis and Endometriosis-Associated Ovarian Carcinomas. Int J Mol Sci. 2013; 14: 18824-49.

78. Engelman JA. Targeting PI3K signalling in cancer: opportunities, challenges and limitations. Nat Rev Cancer. 2009; 9: 550-62.

79. Khwaja A. Akt is more than just a Bad kinase. Nature. 1999; 401: 33-4

80. Chene G, Ouellet V, Rahimi K, et al. The ARID1A pathway in ovarian clear cell and endometrioid carcinoma, contiguous endometriosis, and benign endometriosis. Int J Gynecol Obstet. 2015; 130: 27-30.

81. Yap TA, Carden CP, Kaye SB. Beyond chemotherapy: targeted therapies in ovarian cancer. Nat Rev Cancer. 2009; 9: 167-81. 
82. Hashiguchi $\mathrm{Y}$, Tsuda $\mathrm{H}$, Inoue $\mathrm{T}$, et al. PTEN expression in clear cell adenocarcinoma of the ovary. Gynecol Oncol. 2006; 101: 71-5.

83. Rahman M, Nakayama K, Rahman MT, et al. Clinicopathologic and biological analysis of PIK3CA mutation in ovarian clear cell carcinoma. Hum Pathol. 2012; 43: 2197-206.

84. Yamamoto S, Tsuda H, Miyai K, et al. Gene amplification and protein overexpression of MET are common events in ovarian clear-cell adenocarcinoma: their roles in tumor progression and prognostication of the patient. Mod Pathol. 2011; 24: 1146-55.

85. Yap TA, Yan L, Patnaik A, et al. First-in-Man Clinical Trial of the Oral Pan-AKT Inhibitor MK-2206 in Patients With Advanced Solid Tumors. J Clin Oncol. 2011; 29: 4688-95

86. Yamamoto S, Tsuda H, Miyai K, et al. Accumulative copy number increase of MET drives tumor development and histological progression in a subset of ovarian clear-cell adenocarcinomas. Mod Pathol. 2012; 25: 122-30.

87. Ma PC, Maulik G, Christensen J, et al. c-Met: Structure, functions and potential for therapeutic inhibition. Cancer Metastasis Rev. 2003; 22: 309-25.

88. Tsuchiya A, Sakamoto M, Yasuda J, et al. Expression profiling in ovarian clear cell carcinoma: identification of hepatocyte nuclear factor-1 beta as a molecular marker and a possible molecular target for therapy of ovarian clear cell carcinoma. Am J Pathol. 2003; 163: 2503-12.

89. Ayhan A, Ertunc D, Tok EC, et al. Expression of the c-Met in advanced epithelial ovarian cancer and its prognostic significance. Int J Gynecol Cancer. 2005; 15: 618-23.

90. Yoriko Y, Shinya A, Kanako S, et al. Met Is the Most Frequently Amplified Gene in Endometriosis-Associated Ovarian Clear Cell Adenocarcinoma and Correlates with Worsened Prognosis. Plos One. 2013; 8: e57724.

91. Kato N, Sasou S, Motoyama T. Expression of hepatocyte nuclear factor-1beta (HNF-1beta) in clear cell tumors and endometriosis of the ovary. Mod Phathol. 2006; 19: 83.

92. Köbel M, Kalloger SE, Carrick J, et al. A limited panel of immunomarkers can reliably distinguish between clear cell and high-grade serous carcinoma of the ovary. Am J Surg Pathol. 2009; 33: 14-21.

93. Kato N, Tamura G, Motoyama T. Hypomethylation of hepatocyte nuclear factor-1beta (HNF-1beta) CpG island in clear cell carcinoma of the ovary. Virchows Archiv. 2008; 452: 175-80.

94. Suzuki E, Kajita S, Takahashi H, et al. Transcriptional upregulation of HNF-1 $\beta$ by NF-kB in ovarian clear cell carcinoma modulates susceptibility to apoptosis through alteration in bcl-2 expression. Lab Invest. 2015; 95: 962-72.

95. Senkel S, Lucas B, Klein-Hitpass L, et al. Identification of target genes of the transcription factor HNF1beta and HNF1alpha in a human embryonic kidney cell line. Biochim Biophys Acta. 2005; 1731: 179-90.

96. Okamoto T, Mandai M, Matsumura N, et al. Hepatocyte nuclear factor- $1 \beta$ (HNF-1 $\beta$ ) promotes glucose uptake and glycolytic activity in ovarian clear cell carcinoma. Mol Carcinog. 2015; 54: 35-49.

97. Tomassetti A, Santis GD, Castellano G, et al. Variant HNF1 modulates epithelial plasticity of normal and transformed ovary cells. Neoplasia. 2008; 10: 1481-92

98. Suryawanshi S, Vlad AM, Lin HM, et al. Plasma microRNAs as novel biomarkers for endometriosis and endometriosis-associated ovarian cancer. Clin Cancer Res. 2013; 19: 1213-24.

99. Moga MA, Bălan A, Dimienescu OG, et al. Circulating miRNAs as Biomarkers for Endometriosis and Endometriosis-Related Ovarian Cancer-An Overview. J Clin Med. 2019; 8: 735.

100. Ohlsson TEMC, Print CG, Louise HM. The role of microRNAs in endometriosis and associated reproductive conditions. Hum Reprod Update. 2010; 16 : 142-65

101. Sato N, Tsunoda H, Nishida M, et al. Loss of heterozygosity on 10q23.3 and mutation of the tumor suppressor gene PTEN in benign endometrial cyst of the ovary: possible sequence progression from benign endometrial cyst to endometrioid carcinoma and clear cell carcinoma of the ovary. Cancer Res. 2000; 60: 7052-6.

102. Dong M, Yang P, Hua F. miR-191 Modulates Malignant Transformation of Endometriosis Through Regulating TIMP3. Med Sci Monit. 2015; 21: 915-20.

103. Calura E, Fruscio R, Paracchini L, et al. miRNA Landscape in Stage I Epithelial Ovarian Cancer Defines the Histotype Specificities. Clin Cancer Res. 2013; 19: 4114-23.

104. Sestito R, Cianfrocca R, Rosanò L, et al. miR-30a inhibits endothelin A receptor and chemoresistance in ovarian carcinoma. Oncotarget. 2016; 7: 4009-23.

105. Nakamura N, Terai $Y$, Nunode M, et al. The differential expression of miRNAs between ovarian endometrioma and endometriosis-associated ovarian cancer. Ovarian Res. 2020; 13: 51

106. Bai L, Wang H, Wang AH, et al. MicroRNA-532 and microRNA-3064 inhibit cell proliferation and invasion by acting as direct regulators of human telomerase reverse transcriptase in ovarian cancer. Plos One. 2017; 12: e0173912.

107. Liu S, Gao S, Wang XY, et al. Expression of miR-126 and Crk in endometriosis: miR-126 may affect the progression of endometriosis by regulating Crk expression. Arch of Gynecol Obstet. 2012; 285: 1065-72.

108. Ebrahimi F, Gopalan V, Smith RA, et al. miR-126 in human cancers: Clinical roles and current perspectives. Exp Mol Pathol. 2014; 96: 98-107.

109. Tomlinson VAL, Newbery HJ, Bergmann JH, et al. Expression of eEF1A2 is associated with clear cell histology in ovarian carcinomas: overexpression of the gene is not dependent on modifications at the EEF1A2 locus. Brit J Cancer. 2007; 96: 1613-20.
110. Chang R, Wang E. Mouse translation elongation factor eEF1A-2 interacts with Prdx-I to protect cells against apoptotic death induced by oxidative stress. J Cell Biochem. 2010; 100: 267-78.

111. Lee Y, Miller HL, Russell HR, et al. McKinnon PJ. Patched2 Modulates Tumorigenesis in Patched1 Heterozygous Mice. Cancer Res. 2006; 66: 6964-71.

112. Tountas NA, Brautigan DL. Migration and retraction of endothelial and epithelial cells require PHI-1, a specific protein-phosphatase-1 inhibitor protein. J Cell Sci. 2004; 117: 5905-12.

113. Mcconechy MK, Anglesio MS, Kalloger SE, et al. Huntsman DG. Subtypespecific mutation of PPP2R1A in endometrial and ovarian carcinomas. J Pathol. 2015; 223: 567-73.

114. Kalra RS, Bapat SA. Enhanced levels of double-strand DNA break repair proteins protect ovarian cancer cells against genotoxic stress-induced apoptosis. J Ovarian Res. 2013; 6: 66.

115. Sagi A, Yeela S, Liron B, et al. Niche-Dependent Gene Expression Profile of Intratumoral Heterogeneous Ovarian Cancer Stem Cell Populations. Plos One. 2013; 8: e83651.

116. Kuroda T, Hirohashi Y, Torigoe T, et al. ALDH1-High Ovarian Cancer StemLike Cells Can Be Isolated from Serous and Clear Cell Adenocarcinoma Cells, and ALDH1 High Expression Is Associated with Poor Prognosis. Plos One. 2013; 8: e65158.

117. Schuettengruber B, Chourrout D, Vervoort M, et al. Genome regulation by polycomb and trithorax proteins. Cell. 2007; 128: 735-45.

118. Ben-Porath I, Thomson MW, Carey VJ, et al. An embryonic stem cell-like gene expression signature in poorly differentiated aggressive human tumors. Nat Genet. 2008; 40: 499-507.

119. Tong IL, Jenner RG, Boyer LA, et al. Control of developmental regulators by Polycomb in human embryonic stem cells. Cell. 2006; 125: 301-13.

120. Mikkelsen TS, Ku M, Jaffe DB, et al. Genome-wide maps of chromatin state in pluripotent and lineage-committed cells. Nature. 2007; 448: 553-60.

121. Hussein SMI, Puri MC, Tonge PD, et al. Genome-wide characterization of the routes to pluripotency. Nature. 2014; 516: 198-206.

122. Chau YY, Hastie ND. The role of Wt1 in regulating mesenchyme in cancer, development, and tissue homeostasis. Trends Genet. 2012; 28: 515-24.

123. Wilson BG, Wang X, Shen X, et al. Epigenetic Antagonism between Polycomb and SWI/SNF Complexes during Oncogenic Transformation. Cancer Cell. 2011; 18: 316-28.

124. Kurman RJ, Shih IM. Molecular pathogenesis and extraovarian origin of epithelial ovarian cancer--shifting the paradigm. Hum Pathol. 2011; 42: 918-31.

125. Son JH, Yoon S, Kim S, et al. Clinicopathologic characteristics of ovarian clear cell carcinoma in the background of endometrioma: A surveillance strategy for an early detection of malignant transformation in patients with asymptomatic endometrioma. Obstet Gynecol Sci. 2019; 62: 27-34.

126. Kumar S, Munkarah A, Arabi H, et al. Prognostic analysis of ovarian cancer associated with endometriosis. Am J Obstet Gynecol. 2011; 204: 63.e1-.e7.

127. Kobayashi H, Kajiwara H, Kanayama S, et al. Molecular pathogenesis of endometriosis-associated clear cell carcinoma of the ovary (review). Oncol Rep. 2009; 22: 233-40.

128. Melin A, Sparén P, Persson I, et al. Endometriosis and the risk of cancer with special emphasis on ovarian cancer. Hum Reprod. 2006; 21: 1237-42.

129. Murta EFC, Nomelini RS, Ferreira FA, et al. Ovarian clear cell carcinoma associated with endometriosis: a case report with immunohistochemical study. Eur J Gynaecol Oncol. 2007; 28: 403-5.

130. He ZX, Shi HH, Fan QB, et al. Predictive factors of ovarian carcinoma for women with ovarian endometrioma aged 45years and older in China. J Ovarian Res. 2017; 10: 45

131. Taniguchi F. New knowledge and insights about the malignant transformation of endometriosis. J Obstet Gynaecol Res. 2017; 43: 1093-100.

132. Haraguchi H, Koga K, Takamura M, et al. Development of ovarian cancer after excision of endometrioma. Fertil Steril. 2016; 106: 1432-7.e.

133. Kobayashi H, Sumimoto K, Kitanaka T, et al. Ovarian endometrioma--risks factors of ovarian cancer development. Eur J Obstet Gynecol Reprod Biol. 2008; 138: 187-93.

134. Thomsen LH, Schnack TH, Buchardi K, et al. Risk factors of epithelial ovarian carcinomas among women with endometriosis: a systematic review. Acta Obstet Gynecol Scand. 2016; 96: 761-78.

135. Varma R, Rollason T, Gupta JK, et al. Endometriosis and the neoplastic process. Reproduction. 2004; 127: 293-304.

136. Brinton LA, Lamb EJ, Moghissi KS, et al. Ovarian cancer risk associated with varying causes of infertility. Fertil Steril. 2004; 82: 405-14.

137. Stewart LM, Holman CDAJ, Aboagye-Sarfo P, et al. In vitro fertilization, endometriosis, nulliparity and ovarian cancer risk. Gynecol Oncol. 2013; 128: 260-4

138. Tang H, Yan L, Xiao W, et al. Clear cell carcinoma of the ovary: Clinicopathologic features and outcomes in a Chinese cohort. Medicine. 2018; 97: e10881.

139. Lee HY, Hong JH, Byun JH, et al. Clinical Characteristics of Clear Cell Ovarian Cancer: A Retrospective Multicenter Experience of 308 Patients in South Korea. Cancer Res Treat. 2020; 52: 277-83.

140. Lee YY, Kim TJ, Kim MJ, et al. Prognosis of ovarian clear cell carcinoma compared to other histological subtypes: A meta-analysis. Gynecol Oncol. 2011; 122 : 541-7.

141. Modugno F, Ness RB, Allen GO, et al. Oral contraceptive use, reproductive history, and risk of epithelial ovarian cancer in women with and without endometriosis. Am J Obstet Gynecol. 2004; 191: 733-40. 
142. Rosenblatt KA, Thomas DB. Reduced risk of ovarian cancer in women with a tubal ligation or hysterectomy. The World Health Organization Collaborative Study of Neoplasia and Steroid Contraceptives. Cancer Epidemiol Biomarkers Prev. 1996; 5: 933-5.

143. Rice MS, Hankinson SE, Tworoger SS. Tubal ligation, hysterectomy, unilateral oophorectomy, and risk of ovarian cancer in the Nurses' Health Studies. Fertil Steril. 2014; 102: 192-8.e3.

144. Melin AS, Lundholm C, Malki N, et al. Hormonal and surgical treatments for endometriosis and risk of epithelial ovarian cancer. Acta Obstet Gynecol Scand. 2013; 92: 546-54

145. Wang KC, Chang WH, Lee WL, et al. An increased risk of epithelial ovarian cancer in Taiwanese women with a new surgico-pathological diagnosis of endometriosis. BMC Cancer. 2014; 14: 831. 